\title{
Influence of state anxiety and trate anxiety in postoperative in oral surgery
}

\author{
Daniel Torres-Lagares, Concha Recio-Lora, Gabriel Castillo-Dalí, Gonzalo Ruiz-de-León-Hernández, Pilar \\ Hita-Iglesias, Maria-Angeles Serrera-Figallo, Juan-José Segura-Egea, José-Luis Gutiérrez-Pérez
}

Master in Oral Surgery. University of Seville, Spain

\author{
Correspondence: \\ Facultad de Odontología de Sevilla \\ C/ Avicena s/n 41009 \\ Sevilla, Spain \\ danieltl@us.es
}

Received: $13 / 10 / 2013$

Accepted: 01/12/2013

\author{
Torres-Lagares D, Recio-Lora C, Castillo-Dalí G, Ruiz-de-León-Hernán- \\ dez G, Hita-Iglesias P, Serrera-Figallo MA, Segura-Egea JJ, Gutiérrez- \\ Pérez JL. Influence of state anxiety and trate anxiety in postoperative in \\ oral surgery. Med Oral Patol Oral Cir Bucal. 2014 Jul 1;19 (4):e403-8. \\ http://www.medicinaoral.com/medoralfree01/v19i4/medoralv19i4p403.pdf

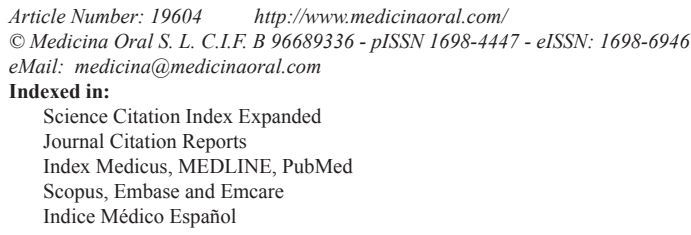

\begin{abstract}
Introduction: The aim of this article was to study the influence of anxiety (both state and trait) in postoperative recovery after extraction of third molar together, to establish the role of each of the aspects of anxiety in the results you obtained in an independent and complementary way.

Material and Methods: We performed a prospective study of a consecutive series of 88 patients who underwent lower third molar extractions. Before being provided with any information about the operation, patients were asked to complete the Spielberger State-Trait Anxiety Inventory-Trait and State. We have evaluated postoperative swelling and pain, patients completed a 10-point visual analog scale (VAS) at home each day (at approximately the same time of day as the operation) until day 8 after surgery, when the sutures were removed.

Results: Regarding postoperative variables between positive and negative trait anxiety groups, consumption of analgesic drugs was higher in positive trait anxiety group in a statistically significant way, while these differences were detected only on specific occasions regarding pain and swelling.

Discussion: In the present study, anxiety was taken into account and showed a significant effect in explaining postoperative pain and taking analgesics.
\end{abstract}

Key words: Anxiety, satisfaction, third molar surgery, Spielberger state-trait anxiety inventory.

\section{Introduction}

Anxiety is an emotional reaction defined as tension (stress), apprehension, nervousness and concerns caused by an intangible and diffuse advancing threat or approaching danger, accompanied by activation of the autonomous nervous system (1).

Moderate to severe acute postoperative pain occurs fre- quently after different surgical procedures and involves up to $50 \%$ of hospitalized patients and $40 \%$ of patients undergoing ambulatory surgery (2).

An aspect that is far from completely clear is the wide variation in patients' experiences of pain after similar types of surgical injury (3).

Numerous authors studied the influence of anxiety in 
the experience of pain (measured in an objective as well as in a subjective way) suffered by the patient during and after the surgery $(2,3)$. The fact that individual put face to surgery with high levels of anxiety may have negative influences in postsurgical physical and mental recovery, such as long hospital stays or greater need for analgesics, which means a harmful both to the individual and the health system by its high cost $(4,5)$.

Anxiety has been studied in two ways: as a personality trait (in which case we refer to it as trait anxiety) and as state of the person (in which case we refer to it state anxiety).

Trait anxiety is a relatively stable tendency toward the kind of anxiety that anyone can suffer when facing situations perceived as threatening. (1) State anxiety is felt as a transitory emotional condition of the human body, characterized by subjective and consciously perceived strain and apprehension feelings and by hyperactivity of the autonomic nervous system. State anxiety also includes dental anxiety, an anxious state in a patient caused by dental treatment (1).

Both variables are, in principle, independent. That means that a person with trait anxiety may not present a state anxiety at one time and a person without this trait in his personalit can manifest anxiety. The influence of both variables related to anxiety, trait and state, regarding postoperative variables, has been approached in several studies (6).

However, these studies have not been observed in a complementary but isolated way, and using different scales that make it difficult to compare results (6-8).

The aim of this article is to study the influence of anxiety (both state and trait) in postoperative recovery after extraction of third molar together, to establish the role of each of the aspects of anxiety in the results you obtained in an independent and complementary way.

\section{Material and Methods}

\section{- Patient selection}

Between January 2009 and July 2009, we performed a prospective study of a consecutive series of 88 patients who underwent lower third molar extractions. We excluded patients who did not comply with the formal requirements of the study (exclusion criteria: patients that have undergone further oral surgery; patients that don't consent to participate; patients with impaired cognitive and communication abilities; patients with history of anxiety attacks and anxiolytic treatment; patients which questionnaires have errors; patients which lower third molar extraction lasted more than 30 minutes (because with this duration, we applied a pharmacological treatment different (corticoids). The sample was composed of 88 patients undergoing a lower third molar removal for the first time (43 left and 45 right), 57 (64,8\%) of whom were women and $31(35,2 \%)$ men.
Patient mean age was 30,4 years $\pm 10,1$. All patients were healthy, with no serious medical conditions or blood dyscrasia. None of the patients had acute pericoronitis or severe periodontal disease at the time of surgery.

- Anxiety evaluation

Before being provided with any information about the operation (60 minutes before), patients were asked to complete the Spielberger State-Trait Anxiety InventoryTrait (STAI-T) (1). This 20-item self-evaluation questionnaire is scored using a 4-level frequency scale, ranging from "almost never" to "almost always," reflecting different degrees of anxiety about situations that subjects perceive as threatening. The patients were subsequently informed about the surgery and postoperative recovery. Before entering the treatment room (30 minutes before), patients, by themselves and in a quiet "non-dental" room, filled out the Spielberger State-Trait Anxiety Inventory- State (STAI-S) (1). The STAI-S (1) is a 20-item self-evaluation questionnaire, scored using a 4-level frequency scale ranging from 0 to 3 , that assesses transient emotional state or condition as characterized by subjective feelings of tension and apprehension that can fluctuate in time and intensity. Social profile data were also taken (profession, age, sex y marital status).

The positive level for STAI-T and STAI-S was, from 0 to 60 , of 20 for the young men (percentile 50 in studies of validation of the above mentioned questionnaire) and of 22 for young women (percentile 50 in studies of validation of the above mentioned questionnaire).

- Surgical Procedure

All interventions were performed by postgraduate students at the University of Seville (Spain) with the same training level. A total of eight surgeons made the surgical treatments. Surgery was in all cases performed under local nerve-block anesthesia of the inferior dental nerve, lingual nerve, and buccal nerve with 2 x $1.8-\mathrm{ml}$ capsules of 4\% articaine with 1:200,000 epinephrine (Articaine; Inibsa, Barcelona, Spain). A mucoperiosteal flap was raised by incision distal to the lower second molar along the length of the anterior border of the ascending ramus of the mandible, with another incision mesial to the same molar. Osteotomy, coronal section, or root section was then performed as required, and the wound was closed with 3/0 silk. A piece of folded gauze was applied to the wound to aid hemostasis.

All patients received an antibiotic (amoxicillin 500 $\mathrm{mg} / 8 \mathrm{~h}$ for 7 days, starting the day before surgery), and an antiinflammatory/analgesic agent (ibuprofen $600 \mathrm{mg}$ on demand, with a maximum of 8 tablets per day, for 7 days starting after surgery). Patients were also given appropriate instructions and recommendations regarding the postoperative recovery period. The sutures were removed 1 week later.

- Evaluation of postoperative

To evaluate postoperative swelling and pain, patients com- 
pleted a 10-point visual analog scale (VAS) of $10 \mathrm{~mm}$ of length (marking at the beginning "no pain" or "no swelling", and at the end "the worst pain possible" or "the worst swelling possible") (9) at home each day (at approximately the same time of day as the operation) until day 8 after surgery, when the sutures were removed. Patients were also informed of the need of record the analgesic medication taken during the different days of the study.

- Statistical analysis

Data collected were entered into an MS-Excel data table (Microsoft Corp. - EE.UU.) and exported to SPSS for Windows v.11 (SPSS Inc. - EE.UU.). Normality of data were confirmed by Kolmogorov-Smirnov test, comparing the averages of the different study groups by the $t$ of Student and ANOVA tests with later Bonferroni test. Later, statistical power analysis was made.

\section{Results}

Our study included 88 patients. 30 of them presented anxiety as personality trait $(37,5 \%)$ and 41 presented anxiety state in the study $(45,4 \%)$.

Regarding postoperative variables between positive and negative trait anxiety groups (Table 1), we can see that consumption of analgesic drugs was higher in positive trait anxiety group in a statistically significant way, almost every day of the study, while these differences were detected only on specific occasions regarding pain (at the end of the study period) and swelling (at the beginning of the study period).

In relation to the difference between the studied variables regarding the positive trait anxiety compared to the negative group (Table 2), no differences were found in relation to the consumption of drugs, while statistically significant differences were found in relation to pain during the whole study period, ant to swelling at the beginning of it.

Crossing both variables (state anxiety (SA) and trait anxiety (TA)) we founded that 20 patients presented positive SA (+) and negative TA (-) $(22,72 \%), 9$ patients presented SA- and $\mathrm{T}+(10,22 \%), 21$ patients presented $\mathrm{SA}+$ and $\mathrm{TA}+(23,86 \%)$, and 38 patients presented $\mathrm{SA}-$ and TA- (43,18\%) (Table 3$)$.

Edema did not show statistically significant values among the four groups. Taking drugs was higher in $\mathrm{TA}+\mathrm{SA}$ - group tan in TA-SA- group in the last days of the study.

Perceived pain was higher in $\mathrm{TA}+\mathrm{SA}+$ than in the rest of groups during all days of the study, and these differences were statistically significant from the second to the seventh day of the study.

Regarding the distribution of positive trait anxiety compared to positive state anxiety (Table 4), patients with positive trait anxiety presented positive state anxiety in a $70 \%$ (21 out of 30 ) while in patients with negative trait

Table 1. Data concerning the assessment of pain, swelling and pain medication as making the appearance of trait anxiety in patients in the sample.

\begin{tabular}{|c|c|c|c|c|}
\hline \multicolumn{2}{|c|}{ Variable } & \multirow{2}{*}{$\begin{array}{c}\begin{array}{c}\text { Trait anxiety } \\
(+)(\mathbf{n}=\mathbf{3 0})\end{array} \\
5,57 \pm 3,14\end{array}$} & \multirow{2}{*}{$\begin{array}{c}\text { Trait anxiety } \\
(-\mathbf{)}(\mathbf{n}=\mathbf{5 8}) \\
4,67 \pm 3,31\end{array}$} & \multirow{2}{*}{$\begin{array}{r}\mathbf{p}<\mathbf{0 , 0 5} \\
0,226\end{array}$} \\
\hline \multirow{8}{*}{$\begin{array}{c}\text { Pain } \\
(\mathbf{E V A}, \mathbf{m m})\end{array}$} & 6 hours & & & \\
\hline & 2 days & $4,79 \pm 3,47$ & $4,12 \pm 3,32$ & 0,384 \\
\hline & 3 days & $4,62 \pm 3,61$ & $3,50 \pm 2,83$ & 0,117 \\
\hline & 4 days & $3,86 \pm 3,46$ & $2,83 \pm 2,44$ & 0,114 \\
\hline & 5 days & $3,48 \pm 3,70$ & $2,40 \pm 2,54$ & 0,112 \\
\hline & 6 days & $3,28 \pm 3,62$ & $1,95 \pm 2,24$ & 0,038 \\
\hline & 7 days & $3,14 \pm 3,45$ & $1,71 \pm 2,47$ & 0,029 \\
\hline & 8 days & $2,45 \pm 3,34$ & $1,41 \pm 2,21$ & 0,089 \\
\hline \multirow{8}{*}{$\begin{array}{c}\text { Swelling } \\
\text { (EVA, mm) }\end{array}$} & 6 hours & $4,31 \pm 3,37$ & $3,33 \pm 3,02$ & 0,173 \\
\hline & 2 days & $5,52 \pm 3,15$ & $3,84 \pm 2,96$ & 0,017 \\
\hline & 3 days & $4,83 \pm 3,24$ & $3,62 \pm 2,78$ & 0,075 \\
\hline & 4 days & $3,76 \pm 3,20$ & $3,22 \pm 2,58$ & 0,404 \\
\hline & 5 days & $3,07 \pm 3,07$ & $2,50 \pm 2,44$ & 0,351 \\
\hline & 6 days & $2,31 \pm 2,81$ & $1,86 \pm 2,08$ & 0,404 \\
\hline & 7 days & $1,86 \pm 2,65$ & $1,22 \pm 1,86$ & 0,194 \\
\hline & 8 days & $1,41 \pm 2,35$ & $0,74 \pm 1,11$ & 0,073 \\
\hline \multirow{8}{*}{$\begin{array}{c}\text { Taking } \\
\text { analgesics } \\
\left(n^{0} \text { of tablets) }\right.\end{array}$} & 6 hours & $1,00 \pm 0,00$ & $0,83 \pm 0,38$ & 0,017 \\
\hline & 2 days & $3,03 \pm 0,18$ & $2,48 \pm 1,14$ & 0,012 \\
\hline & 3 days & $3,03 \pm 0,18$ & $2,41 \pm 1,18$ & 0,006 \\
\hline & 4 days & $2,86 \pm 0,87$ & $2,21 \pm 1,32$ & 0,018 \\
\hline & 5 days & $2,55 \pm 1,24$ & $1,95 \pm 1,43$ & 0,047 \\
\hline & 6 days & $2,45 \pm 1,32$ & $1,60 \pm 1,50$ & 0,012 \\
\hline & 7 days & $2,28 \pm 1,30$ & $1,40 \pm 1,50$ & 0,009 \\
\hline & 8 days & $2,07 \pm 1,41$ & $1,24 \pm 1,49$ & 0,015 \\
\hline
\end{tabular}


Table 2. Data concerning the assessment of pain, swelling and pain medication as making the appearance of state anxiety in patients in the sample.

\begin{tabular}{|c|c|c|c|c|}
\hline \multicolumn{2}{|c|}{ Variable } & \multirow{2}{*}{$\begin{array}{c}\begin{array}{c}\text { State anxiety } \\
(+)(\mathbf{n}=\mathbf{4 1})\end{array} \\
6,02 \pm 3,00\end{array}$} & \multirow{2}{*}{$\begin{array}{c}\text { State anxiety } \\
(-)(\mathbf{n}=\mathbf{4 7})\end{array}$} & \multirow{2}{*}{$\begin{array}{c}\mathbf{p}<\mathbf{0 , 0 5} \\
0,004\end{array}$} \\
\hline \multirow{8}{*}{$\begin{array}{c}\text { Pain } \\
(\text { EVA, mm) }\end{array}$} & 6 hours & & & \\
\hline & 2 days & $5,90 \pm 3,09$ & $3,02 \pm 3,04$ & 0,001 \\
\hline & 3 days & $5,20 \pm 3,13$ & $2,74 \pm 2,69$ & 0,001 \\
\hline & 4 days & $4,15 \pm 3,13$ & $2,34 \pm 2,35$ & 0,003 \\
\hline & 5 days & $3,83 \pm 3,41$ & $1,85 \pm 2,26$ & 0,002 \\
\hline & 6 days & $3,30 \pm 3,24$ & $1,62 \pm 2,17$ & 0,005 \\
\hline & 7 days & $3,08 \pm 3,19$ & $1,43 \pm 2,41$ & 0,007 \\
\hline & 8 days & $2,45 \pm 3,08$ & $1,17 \pm 2,13$ & 0,025 \\
\hline \multirow{8}{*}{$\begin{array}{c}\text { Swelling } \\
\text { (EVA, mm) }\end{array}$} & 6 hours & $4,55 \pm 3,23$ & $2,89 \pm 2,92$ & 0,014 \\
\hline & 2 days & $5,38 \pm 3,05$ & $3,57 \pm 2,94$ & 0,006 \\
\hline & 3 days & $4,93 \pm 2,97$ & $3,26 \pm 2,79$ & 0,008 \\
\hline & 4 days & $4,03 \pm 2,86$ & $2,87 \pm 2,65$ & 0,055 \\
\hline & 5 days & $3,18 \pm 2,70$ & $2,28 \pm 2,55$ & 0,118 \\
\hline & 6 days & $2,45 \pm 2,43$ & $1,64 \pm 2,22$ & 0,108 \\
\hline & 7 days & $2,78 \pm 2,17$ & $1,15 \pm 2,10$ & 0,177 \\
\hline & 8 days & $1,35 \pm 1,88$ & $0,64 \pm 1,35$ & 0,051 \\
\hline \multirow{8}{*}{$\begin{array}{c}\text { Taking } \\
\text { analgesics } \\
\left(\mathrm{n}^{\mathbf{0}} \text { of tablets) }\right.\end{array}$} & 6 hours & $0,95 \pm 0,22$ & $1,83 \pm 0,38$ & 0,081 \\
\hline & 2 days & $2,88 \pm 0,68$ & $2,49 \pm 1,14$ & 0,065 \\
\hline & 3 days & $2,85 \pm 0,70$ & $2,43 \pm 1,19$ & 0,051 \\
\hline & 4 days & $2,53 \pm 1,21$ & $2,34 \pm 1,23$ & 0,487 \\
\hline & 5 days & $2,15 \pm 1,46$ & $2,15 \pm 1,35$ & 0,997 \\
\hline & 6 days & $2,00 \pm 1,58$ & $1,79 \pm 1,48$ & 0,512 \\
\hline & 7 days & $1,95 \pm 1,44$ & $1,47 \pm 1,51$ & 0,135 \\
\hline & 8 days & $1,80 \pm 1,48$ & $1,28 \pm 1,49$ & 0,107 \\
\hline
\end{tabular}

Table 3. Data concerning the assessment of pain, swelling and pain medication as making the appearance of state anxiety or trait anxiety in patients in the sample. (The superscripts indicate, in the same row, the data pairs with statistically significant differences in the Bonferroni test $(p<0,005)$.

\begin{tabular}{|c|c|c|c|c|c|c|}
\hline \multicolumn{2}{|l|}{ Variable } & $\begin{array}{c}\text { Trait anxiety }(+)- \\
\text { State anxiety }(+) \\
(n=21)\end{array}$ & $\begin{array}{c}\text { Trait anxiety }(-)- \\
\text { State anxiety }(+) \\
(\mathbf{n}=\mathbf{2 0})\end{array}$ & $\begin{array}{c}\text { Trait anxiety }(+)- \\
\text { State anxiety }(-) \\
(n=9)\end{array}$ & $\begin{array}{c}\text { Trait anxiety (-) - } \\
\text { State anxiety (-) } \\
(\mathrm{n}=\mathbf{3 8}) \\
\end{array}$ & $\mathrm{p}<0,05$ \\
\hline \multirow{8}{*}{$\begin{array}{c}\text { Pain } \\
\text { (EVA, mm) }\end{array}$} & 6 hours & $6,00 \pm 2,89$ & $6,05 \pm 3,18$ & $4,56 \pm 3,64$ & $4,98 \pm 3,26$ & \\
\hline & 2 days & $6,35 \pm 3,01^{(1)}$ & $5,45 \pm 3,18^{(2)}$ & $1,33 \pm 1,11^{(1,2)}$ & $4,34 \pm 3,73$ & 0,025 \\
\hline & 3 days & $6,00 \pm 3,17^{(1)}$ & $4,40 \pm 2,94$ & $1,56 \pm 2,50^{(1)}$ & $3,87 \pm 3,13$ & 0,008 \\
\hline & 4 days & $5,00 \pm 3,49^{(1,2)}$ & $3,30 \pm 2,53$ & $1,33 \pm 1,58^{(1)}$ & $3,17 \pm 2,87^{(2)}$ & 0,006 \\
\hline & 5 days & $4,70 \pm 3,86^{(1,2)}$ & $2,95 \pm 2,72$ & $0,78 \pm 0,83^{(1)}$ & $2,76 \pm 3,00^{(2)}$ & 0,006 \\
\hline & 6 days & $4,45 \pm 3,76^{(1,2,3)}$ & $2,15 \pm 2,15^{(1)}$ & $0,67 \pm 1,11^{(2)}$ & $2,39 \pm 2,83^{(3)}$ & 0,014 \\
\hline & 7 days & $4,10 \pm 3,61^{(1,2)}$ & $2,05 \pm 2,37$ & $1,00 \pm 1,80^{(1)}$ & $2,18 \pm 2,90^{(2)}$ & 0,025 \\
\hline & 8 days & $3,10 \pm 3,65$ & $1,80 \pm 2,28$ & $1,00 \pm 2,00$ & $1,76 \pm 2,62$ & 0,215 \\
\hline \multirow{8}{*}{$\begin{array}{c}\text { Swelling } \\
\text { (EVA, mm) }\end{array}$} & 6 hours & $4,35 \pm 3,32^{(1)}$ & $4,75 \pm 3,21$ & $4,22 \pm 3,66$ & $3,66 \pm 3,16^{(1)}$ & 0,047 \\
\hline & 2 days & $5,70 \pm 3,11$ & $5,05 \pm 3,03$ & $5,11 \pm 3,40$ & $4,40 \pm 3,11$ & 0,085 \\
\hline & 3 days & $5,20 \pm 3,10$ & $4,65 \pm 2,88$ & $4,00 \pm 3,57$ & $4,02 \pm 2,98$ & 0,424 \\
\hline & 4 days & $4,20 \pm 3,20$ & $3,85 \pm 2,36$ & $2,78 \pm 2,81$ & $3,40 \pm 2,79$ & 0,451 \\
\hline & 5 days & $3,40 \pm 3,20$ & $3,15 \pm 2,18$ & $2,78 \pm 2,90$ & $2,69 \pm 2,66$ & 0,604 \\
\hline & 6 days & $2,55 \pm 2,81$ & $2,35 \pm 2,05$ & $1,78 \pm 2,90$ & $2,01 \pm 2,34$ & 0,234 \\
\hline & 7 days & $1,95 \pm 2,46$ & $1,60 \pm 1,90$ & $1,67 \pm 3,08$ & $1,44 \pm 2,15$ & 0,172 \\
\hline & 8 days & $1,50 \pm 2,32$ & $1,20 \pm 1,36$ & $1,22 \pm 2,83$ & $0,97 \pm 1,65$ & 0,496 \\
\hline \multirow{8}{*}{$\begin{array}{l}\text { Taking analgesics } \\
\text { (n' of tablets) }\end{array}$} & 6 hours & $1,50 \pm 0,00$ & $0,90 \pm 0,38$ & $1,00 \pm 0,00$ & $0,89 \pm 0,32$ & 0,985 \\
\hline & 2 days & $3,05 \pm 0,22$ & $2,70 \pm 0,92$ & $3,00 \pm 0,00$ & $2,67 \pm 0,97$ & 0,412 \\
\hline & 3 days & $3,05 \pm 0,22^{(1)}$ & $2,65 \pm 0,93$ & $3,00 \pm 0,00$ & $2,29 \pm 1,29^{(1)}$ & 0,029 \\
\hline & 4 days & $2,80 \pm 1,05$ & $2,25 \pm 1,33$ & $3,00 \pm 0,00$ & $2,18 \pm 1,33$ & 0,327 \\
\hline & 5 days & $2,35 \pm 1,46$ & $1,95 \pm 1,46$ & $3,00 \pm 0,00$ & $1,95 \pm 1,43$ & 0,343 \\
\hline & 6 days & $2,20 \pm 1,54$ & $1,80 \pm 1,50$ & $3,00 \pm 0,00^{(1)}$ & $1,50 \pm 1,52^{(1)}$ & 0,038 \\
\hline & 7 days & $2,10 \pm 1,41$ & $1,80 \pm 1,50$ & $2,67 \pm 1,00^{(1)}$ & $1,18 \pm 1,48^{(1)}$ & 0,047 \\
\hline & 8 days & $1,95 \pm 1,46$ & $1,65 \pm 1,53$ & $2,33 \pm 1,32$ & $1,03 \pm 1,44$ & 0,560 \\
\hline
\end{tabular}


Table 4. Relationship of the presentation of anxiety as state and trait anxiety in the sample. $(\chi 2, p=0,002)$.

\begin{tabular}{|c|c|c|c|}
\hline & $\begin{array}{c}\text { State } \\
\text { anxiety (+) }\end{array}$ & $\begin{array}{c}\text { State } \\
\text { anxiety (-) }\end{array}$ & \\
\hline Trait anxiety (+) & 21 & 9 & 30 \\
\hline Trait anxiety (-) & 20 & 38 & 58 \\
\hline & 41 & 47 & \\
\hline
\end{tabular}

anxiety this percentage was almost half $(34,48 \% ; 20$ out of 58). This difference was statistically significant.

Statistical power

We have made the statistical power analysis in all the comparisons. For the first test (Table 1) $(30$ and $61 \mathrm{pa}-$ tients, alpha $=0,05$ and beta $=0,2$ (power $80 \%$ )), it might detect a difference of $1,2 \mathrm{~mm}$ in EVA, which is clinical relevant. For the second test (Table 2), it might detect a difference of $1 \mathrm{~mm}$ in EVA with the same characteristics. In the test presented in table 3 , this one would have a power of $80 \%$ to detect changes of $2 \mathrm{~mm}$ in the EVA. To detect a difference of $1 \mathrm{~mm}$ in EVA the power of the test war only $30 \%$. For what the not significant differences established in the above mentioned table must not think like conclusively.

\section{Discussion}

Liddell and Locker, in their study, found that preoperative anxiety decreased with age (10). Hägglin et al. (11) explained that technological advances in dentistry can decrease this anxiety. Liau et al. (12), found that younger patients had higher anxiety, arguing that experience and familiarity are important factors.

In the present study, anxiety was taken into account and showed a significant effect in explaining postoperative pain (state anxiety) and taking analgesics (trait anxiety), however, it fails to point out differences in the edema felt by patients beyond the first few days of the study (state of anxiety). Although relations between negative feeling and pain-related unpleasantness have been found in several studies (7). Taenzer et al. (13) subsequently confirmed that high levels of trait anxiety meant an increased perception of pain, and this has also been confirmed for other types of surgeries $(14,15)$.

Our results are coherent with González-Lemmonier et al. (7) and Vassend (16), and these findings are consistent with those obtained of George et al., (17) who concluded that high levels of trait anxiety were associated with a poorer recovery. We agree with other authors who suggest that pain overestimation and a fear of pain is manifested by people with high dental anxiety (18-20).

Is still under discussion the predictive value of anxiety about postoperative pain. While Vallerand et al. (21) stated even that trait anxiety was an accurate predictor of postoperative pain and oral surgery recovery other authors do not share this opinion (6).
It has been shown that psychological stress can have many physical effects, ranging from increased sympatheticadrenergic activity to illness susceptibility. Stress may even adversely affect physical recovery after surgery. Several studies report a relationship between psychological factors and postsurgical recovery; however, the results are neither clear nor compelling $(9,15,22-24)$.

As pointed out by Hoogenboom and Vielvoye-Kerkmeer (25), our data indicate that the use and effect of painkillers administered after third molar extraction depended on the level of anxiety. In our study, this feature is observed between the groups positive and negative trait anxiety.

It has not been developed before the relationship between trait anxiety dealing with anxiety as a state, as it has been done in our study. Our data indicate that a patient with personality trait anxiety is twice as likely to be anxious (as a state) before dental treatment than a patient without this personality trait.

In relation to the crossing of variables SA and TA, we note that the positive combination of both variables are detected, the highest values of postoperative pain, while the lowest values (even more than the values of SA and TA negative group) are detected in TA+ and SA-, indicating the increased importance of anxiety as a state in this section. However, the few statistically significant differences found relating to the consumption of painkillers are linked to anxiety trait.

The results of our study are of clinical usefulness in two ways. The first one is that the influence of the anxiety strait and trate in the postoperatory is demonstrated. Previously only the influence of the anxiety state had been demonstrated. Therefore, there should be promoted any activity that improves or diminishes the anxiety, being based on its clinical benefits, especially if they are innocuous.

Our information also would support the preoperatory administration of tranquillizers, though this should be evaluated together with the costs and possible risks of the medication.

In conclusion, and according to our data, anxiety influences pain perceived by the patient during the oral surgery postoperative and taking painkillers. However, this does not influence the perception of inflammation during the same period. It also confirms that trait and state components of anxiety influence these clinical values differently.

\section{References}

1. Miller AA. Psychological considerations in dentistry. J Am Dent Assoc. 1970;81:941-8.

2. Janssen KJ, Kalkman CJ, Grobbee DE, Bonsel GJ, Moons KG, Vergouwe Y. The risk of severe postoperative pain: Modification and validation of a clinical prediction rule. Anesth Analg. 2008;107:1330-9.

3. Werner MU, Duun P, Kehlet H. Prediction of postoperative pain by preoperative nociceptive responses to heat stimulation. Anesthesiology. 2004;100:115-9.

4. Devine EC, Cook TD. Clinical and cost-saving effects of psychoe- 
ducational interventions with surgical patients: a meta-analysis. Res Nurs Health. 1986;9:89-105.

5. Sobel DS. Rethinking medicine: improving health outcomes with cost-effective psychosocial interventions. Psychosom Med. 1995;57:234-44.

6. Lago-Méndez L, Diniz-Freitas M, Senra-Rivera C, SeoanePesqueira G, Gándara-Rey JM, García-García A. Postoperative recovery after removal of a lower third molar: role of trait and dental anxiety. Oral Surg Oral Med Oral Pathol Oral Radiol Endod. 2009;108:855-60.

7. González-Lemonnier S, Bovaira-Forner M, Peñarrocha-Diago MA, Peñarrocha-Oltra D. Relationship between preoperative anxiety and postope-rative satisfaction in dental implant surgery with intravenous conscious sedation. Med Oral Patol Oral Cir Bucal. 2010;15:e379-82.

8. Mobilio N, Gremigni P, Pramstraller M, Vecchiatini R, Calura G, Catapano S. Explaining Pain After Lower Third Molar Extraction by Preoperative Pain Assessment. J Oral Maxillofac Surg. 2011;69:2731-8

9. Wolfer JA, Davis CE. Assessment of surgical patients' preoperative emotional condition and postoperative welfare. Nursing Res. 1970;19:402-14.

10. Liddell A, Locker D. Gender and age differences in attitudes to dental pain and dental control. Community Dent Oral Epidemiol. 1997;25:314-8.

11 Hägglin C, Berggren U, Hakeberg M, Hällstrom T, Bengtsson C. Variations in dental anxiety among middle-aged and elderly women in Sweden: a longitudinal study between 1968 and 1996. J Dent Res. 1999:78:1655-61.

12. Liau FL, Kok SH, Lee JJ, Kuo RC, Hwang CR, Yang PJ, et al. Cardiovascular influence of dental anxiety during local anesthesia for tooth extraction. Oral Surg Oral Med Oral Pathol Oral Radiol Endod. 2008;105:16-26.

13. Taenzer P, Melzack R, Jeans ME. Influence of psychological factors on postoperative pain, mood and analgesic requirements. Pain. 1986;24:331-42.

14. Chapman CR, Cox GB. Anxiety, pain, and depression surrounding elective surgery: a multivariate comparison of abdominal surgery patients with kidney donors and recipients. J Psychosom Res. 1977;21:7-15.

15. Martinez-Urrutia A. Anxiety and pain in surgical patients. J Consult Clin Psychol. 1975;43:437-42.

16. Vassend O. Anxiety, pain and discomfort associated with dental treatment. Behav Res Ther. 1993;31:659-66.

17. George JM, Scoct DS, Turner SP, Gregg JM. The effects of psychological and physical trauma on recovery from oral surgery. J Behav Med. 1980;3:291-310.

18. Maggirias J, Locker D. Psychological factors and perceptions of pain associated with dental treatment. Community Dent Oral Epidemiol. 2002;30:151-9.

19. Scott LE, Clum GA, Peoples JB. Preoperative predictors of postoperative pain. Pain. 1983;15:283-93.

20. van Wijk AJ, Hoogstraten J. Experience with dental pain and fear of dental pain. J Dent Res. 2005;84:947-50.

21. Vallerand WP, Vallerand AH, Heft M. The effects of postoperative preparatory information on the clinical course following third molar extraction. J Oral Maxillofac Surg. 1994;52:1165-70.

22. Auerbach SM. Trait-state anxiety and adjustment to surgery. J Consult Clin Psychol. 1973;40:264-71.

23. Cohen F, Lazarus RS. Active coping processes, coping dispositions, and recovery from surgery. Psychosom Med. 1973;35:375-89. 24. Johnson JE, Dabbs JM, Leventhal H. Psychosocial factors in the welfare of surgical patients. Nurs Res. 1970;19:18-29.

25. Hoogenboom LJ, Vielvoye-Kerkmeer APE. Relief of pain due to surgical extraction of the third molar. Pain. 1984;18:109S.

\section{Funding}

None Competing interests: None declared Ethical approval: Not required. 